\title{
DIRECT REPAIR OF THE DEFECT IN SPONDYLOLISTHESIS
}

\section{Preliminary Report}

\author{
J. E. Buck, London, ENGLAND \\ From the Brook General Hospital, London
}

Operations for the relief of symptoms in spondylolisthesis range from simple excision of the loose lamina and spinous process to fusion of three vertebrae from behind or two by the anterior route. Each method has its advocates but a review of techniques by Henderson (1966) concluded that only 65 to 70 per cent of operations gave satisfactory results.

An extensive search of the literature has failed to reveal any description of an operation designed solely to repair the defect in the pars interarticularis which forms the basis of the deformity. Since this defect seems in most cases to be due to non-union of a fatigue fracture,

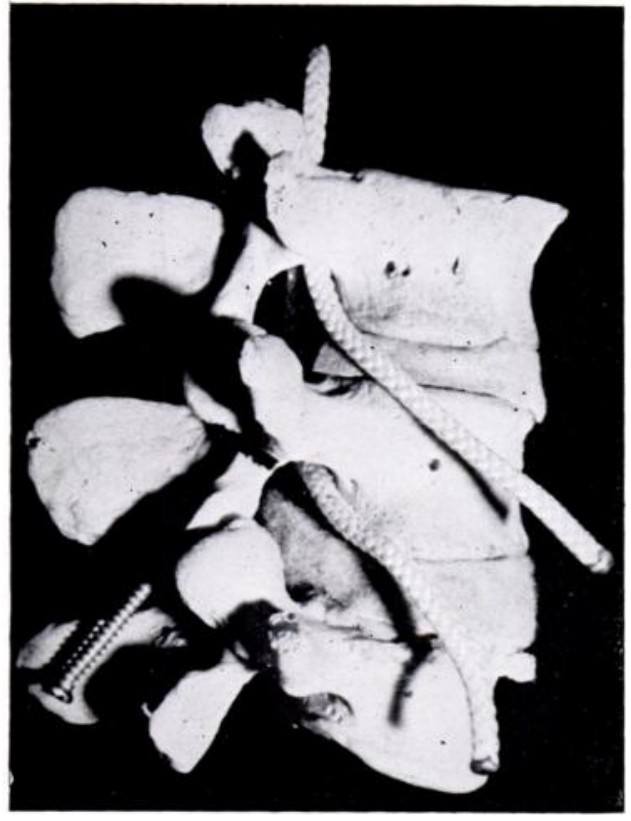

Fig. 1

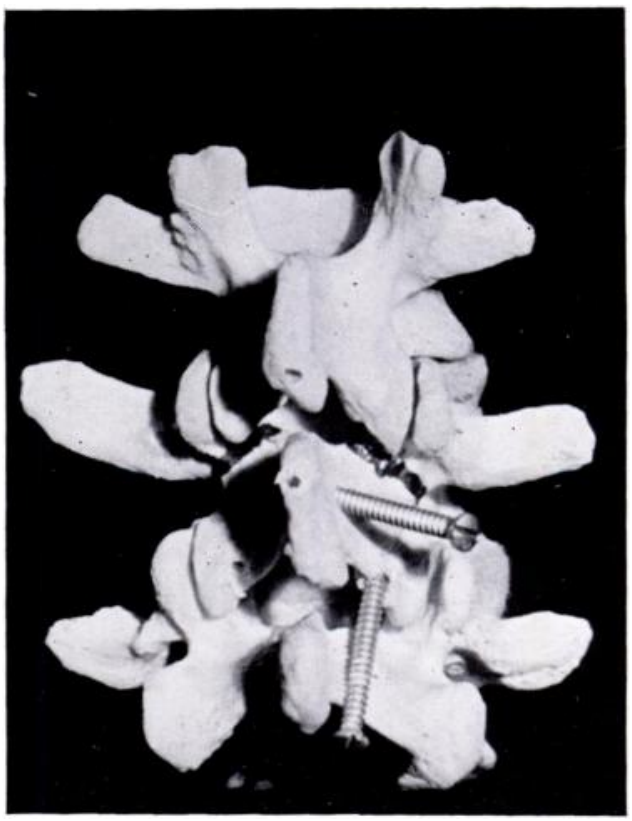

FIG. 2

Figure 1-Lateral view of specimen including the third, fourth and fifth lumbar vertebrae, showing the line of a screw traversing the lamina and pars interarticularis. Figure 2-Posterior view of the same specimen. The screw lying transversely represents an alternative approach which is possible in some cases.

the possibility of fixing the fracture internally and supporting it with a cancellous bone graft was explored. The procedure described in the following account was elaborated and has been used successfully over the past four years.

\section{ANATOMICAL CONSIDERATIONS}

An examination of the anatomy of the lower lumbar vertebrae (Figs. 1 and 2) shows that a screw may be passed along the pars interarticularis and across the area of the defect and yet remain wholly within bone for at least one centimetre on each side of the gap. The screw enters the inferior edge of the lamina and travels upwards, forwards and slightly outwards. 
The relationship of the screw to the two emerging nerves can also be seen (Fig. 1). The entry of the appropriate drill is simplified by taking a small piece of bone off the inferior edge of the lamina with a Trotter's nibbler, thus squaring the normally round edge. Examination of

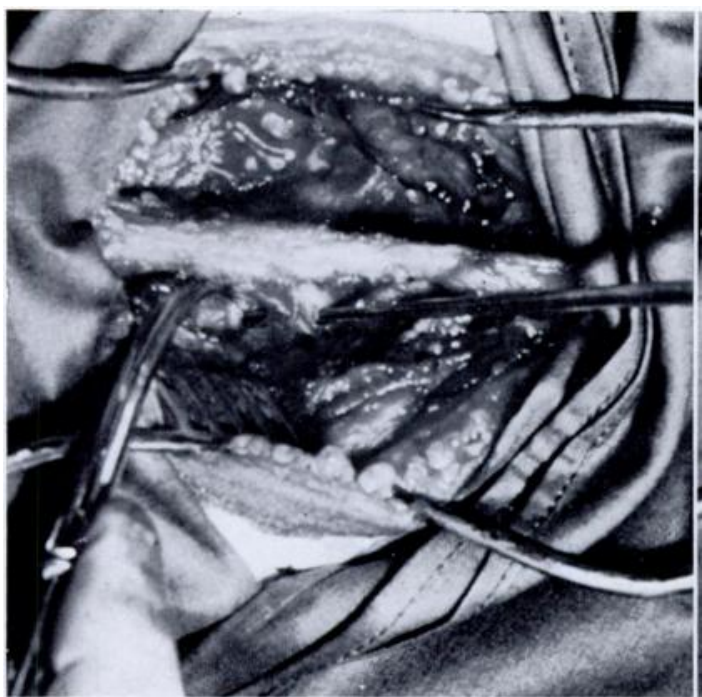

Fig. 3

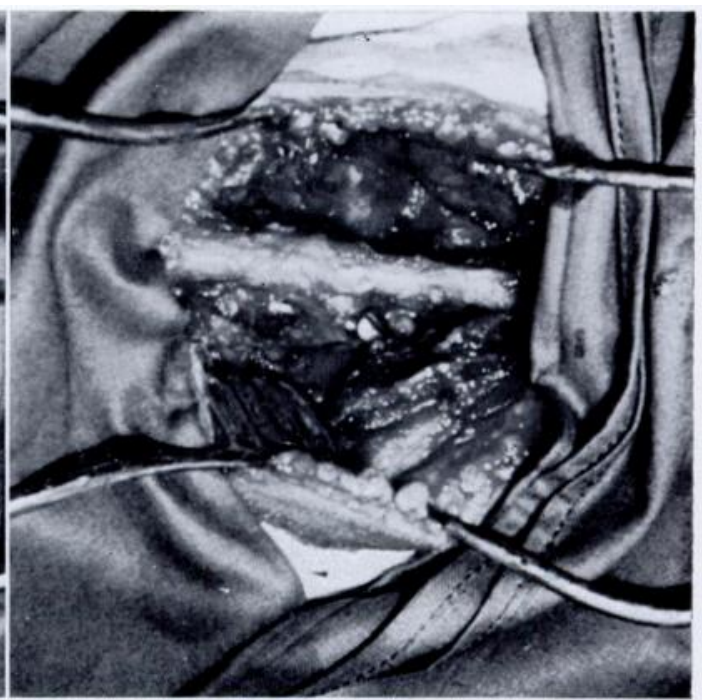

Fig. 4

Figure 3-A probe inserted in the drill hole is seen to cross the defect. The tip of the sucker is over the adjacent joint. Figure 4-The screw in position.

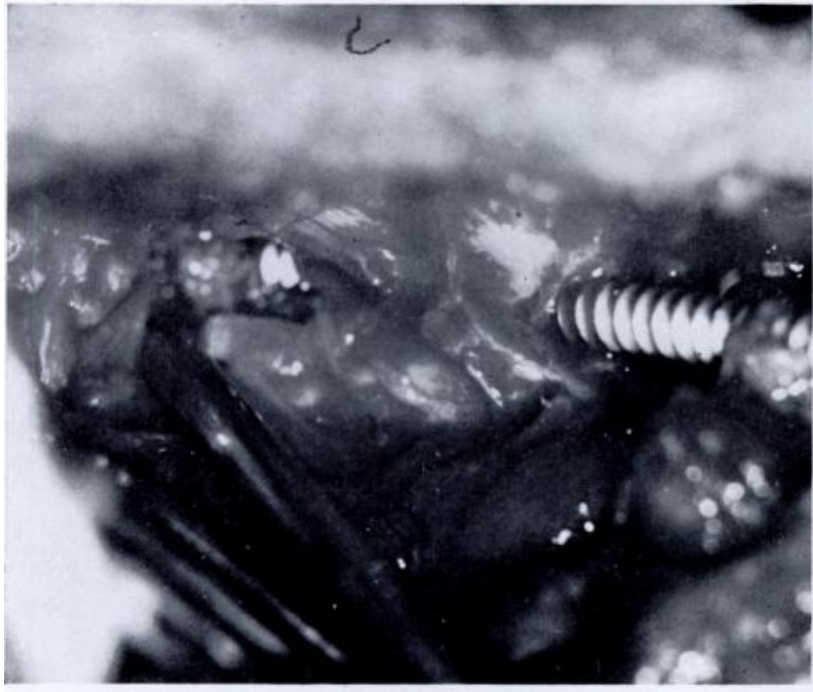

Fig. 5

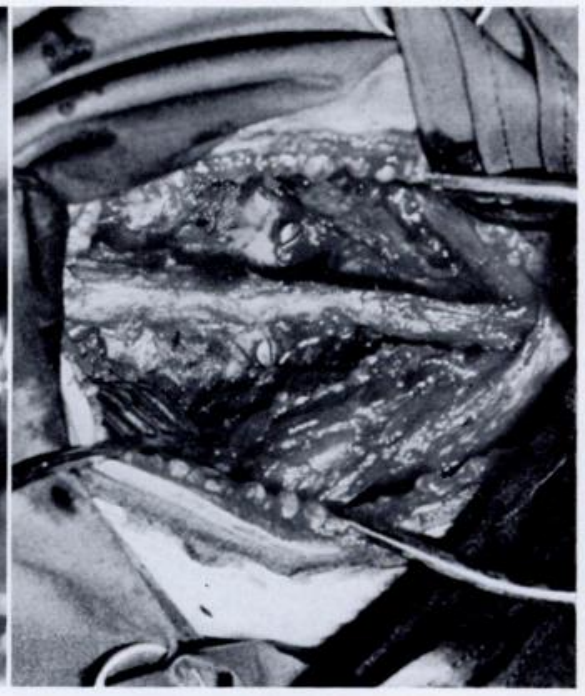

Fig. 6

Figure 5-Close-up photograph of the screw. The sucker tip is again in the joint above. Figure 6-The final appearance of the screws. The defect has been filled with, and surrounded by, bone chips.

the lamina shows that the threads of the screw grip well on the posterior and anterior cortical plates and also on the cortical bone of the pedicular side of the defect.

\section{THE OPERATION}

The operation is carried out through a curved incision over the appropriate lumbar spines, deviating laterally at its lower end to afford access to the posterior part of the iliac crest from VOL. 52 B, NO. 3, AUGUST 1970 
which cancellous bone for the graft is obtained. The loose lamina is cleared forward to the defect and the fibrous tissue in and around the gap is removed. A small angled nibbling forceps is essential here. A drill is then passed up through the lamina and directed so as to cross the defect under vision: alternatively the curved end of a Macdonald's dissector may be introduced into the defect from above and removed when the drill strikes it. The drill will be felt to pass on into solid bone for approximately a centimetre: it is then withdrawn and a screw of the appropriate length is introduced (Figs. 3 to 5). When both screws are in place it will be found that the lamina has become stabilised. The screws are now partly withdrawn, one at a time, to allow bone chips from the ilium to be packed in the defect as well as behind and lateral to it; the screws are then driven home (Fig. 6). The bone chips must be clear of the joint, which lies immediately superior to the defect. The wound is closed with suction drainage.

The patient is allowed up three or four days after the operation. In two cases plaster-ofParis jackets were used to enable the patients to resume housework without risk. In two other cases Glassona glass fibre jackets were applied to allow the patients to swim on holiday and to return to physical activity before fusion had had time to occur.

\section{RESULTS AND ILLUSTRATIVE CASES}

Sixteen patients have been operated on with one failure and two complications as described below.

Case 1-The first operation was carried out in November 1965 in a schoolboy aged fifteen, a keen footballer whose symptoms were severe enough to stop him from playing (Fig. 7). The

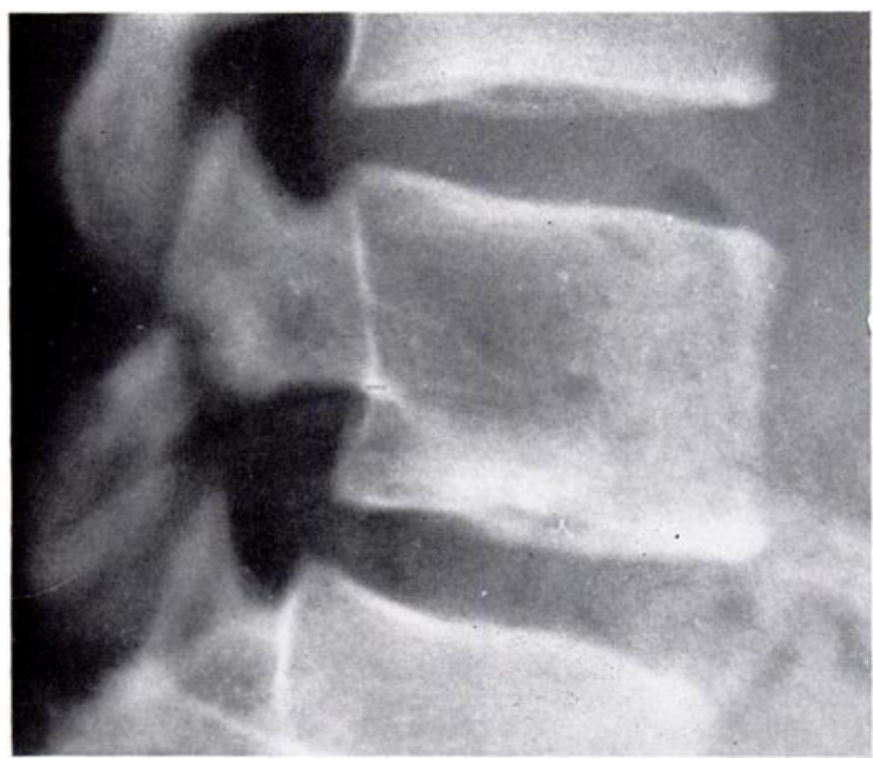

Fig. 7

Case 1-Lateral radiograph before operation. The defect was hardly visible in the oblique radiographs.

patient left hospital two weeks after operation with instructions to avoid bending, lifting and contact sports for a further four weeks. He then undertook gradually increasing training until the radiographs showed sound union (Figs. 8 to 11) and at twelve weeks he was playing football again. He has since had no trouble at all with his back. The radiographs show clearly the correct positioning of the screws in four standard views. 


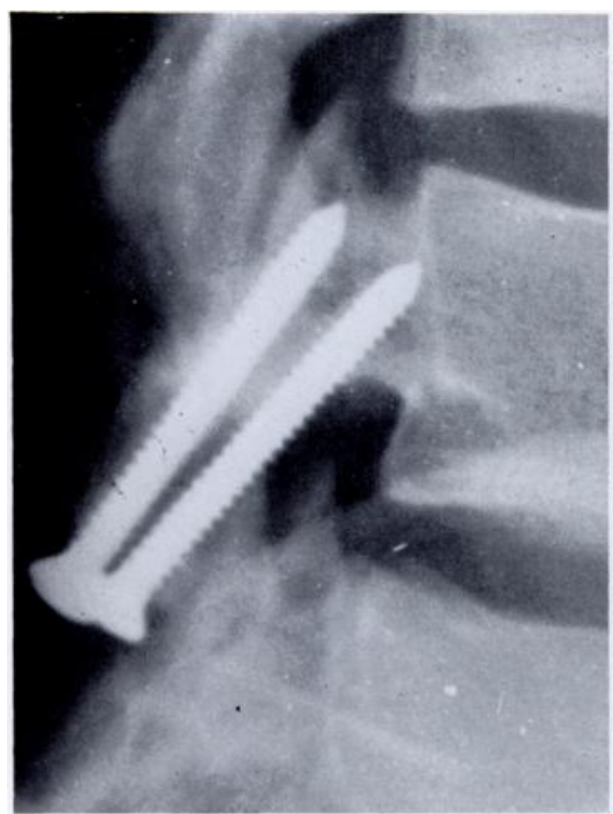

FiG. 8

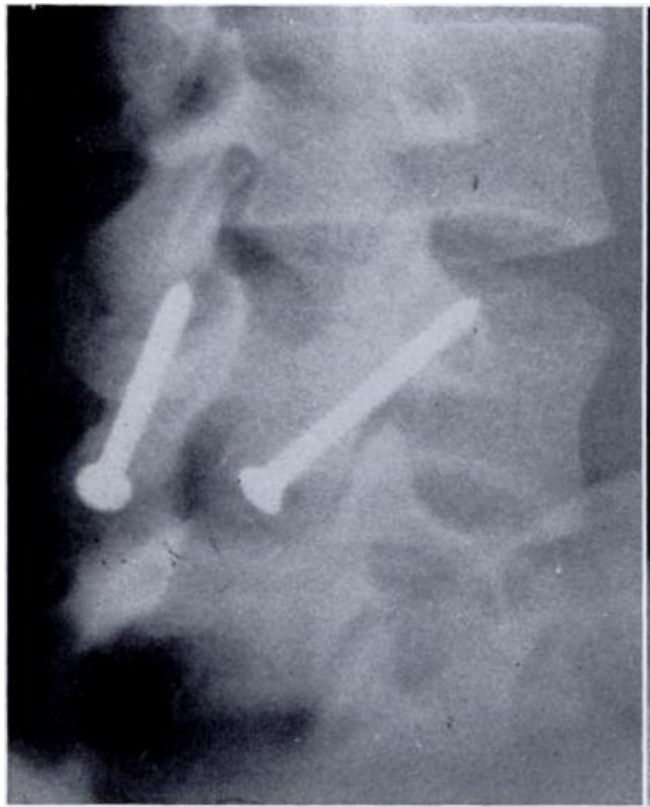

Fig. 10

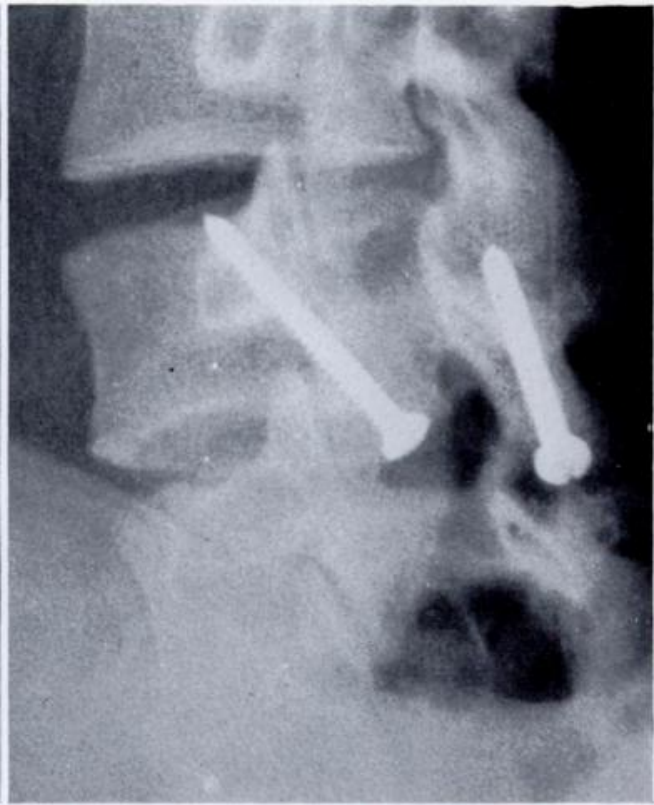

FIG. 9

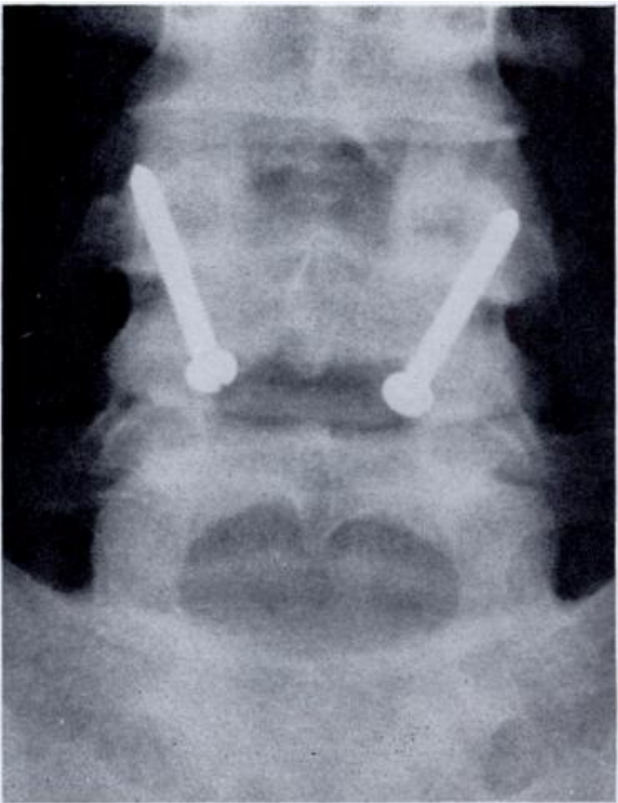

Fig. 11

Case 1-Four standard views taken three months after operation to show the position of the screws. The enlarged lateral view shows the disappearance of the lesion. 
Case 2-Another schoolboy, aged fourteen, was operated upon in May 1968. The radiographs (Figs. 12 to 14) show clearly that fusion has occurred. The boy has resumed playing rugby football and is free from symptoms.

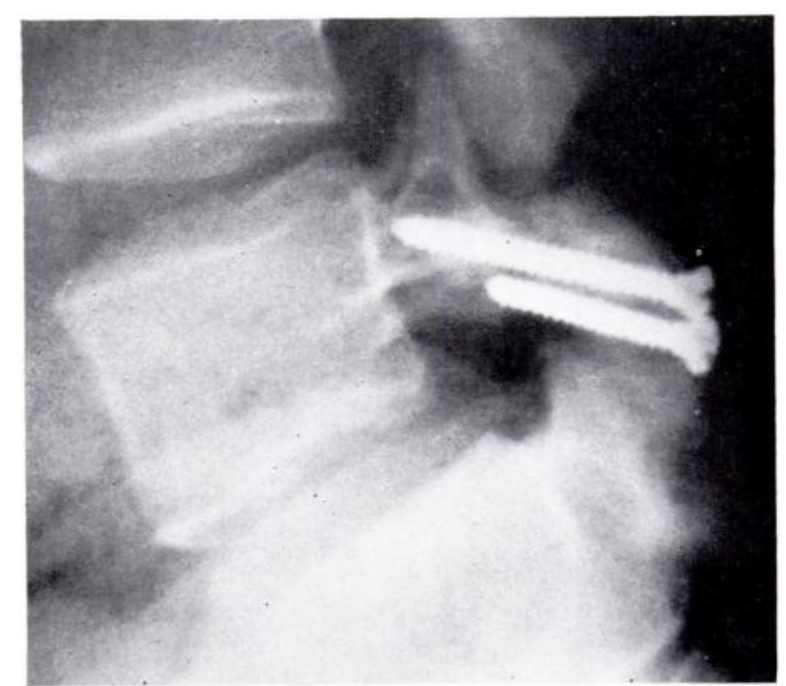

FIG. 12

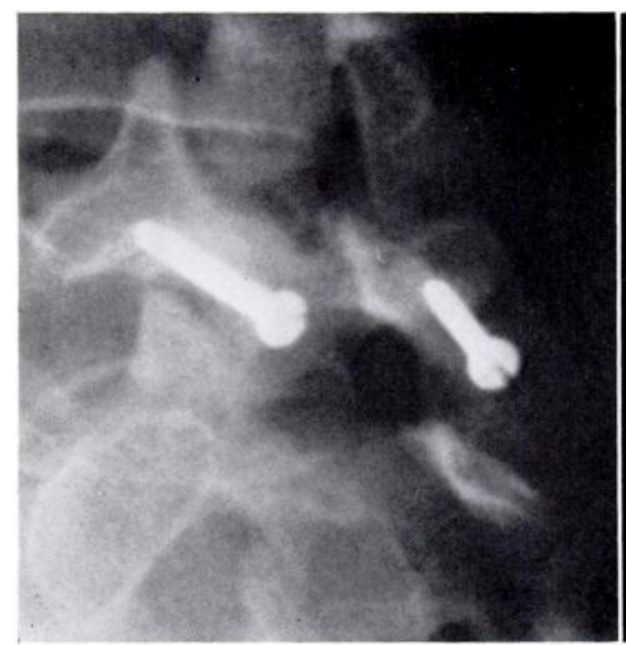

Fig. 13

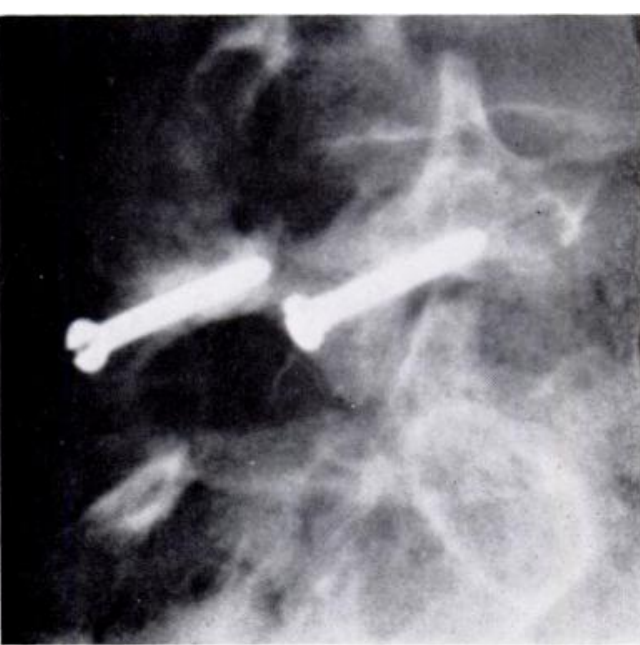

FIG. 14

Case 2-Radiographs eighteen months after operation. The oblique projections show well the trabecular nature of the healing.

Case 3-Another patient, a man aged twenty-one who was operated on in 1966, resumed playing golf three months afterwards but his backache was never completely relieved and over the next six months it gradually increased. Re-exploration after a year showed that both screws had worked loose and the lamina had become unstable again. Posterior fusion was carried out with good relief of symptoms. This represents the one failure in the series. In retrospect it seems likely that the lesion was beyond the practical limit of repair, the gap being about four millimetres.

Case 4-A woman aged twenty-four had a successful repair but fell down a flight of stairs five weeks after operation. She immediately developed sciatica which she had never had before. 
As she also had a compensation claim pending she was treated at first with bed rest, traction, plaster jackets, corsets and tranquillisers. She failed to respond and the spine was re-explored six months after the first operation. The screws were firm and the defects were solidly fused. Removal of the lamina on the affected side together with one screw and the ligamentum flavum relieved the sciatica although no disc protrusion was present.

Case 5-A man aged thirty-four complained of mild but persistent sciatica after operation. A radiograph three months later happened to be taken at a slightly different angle from the

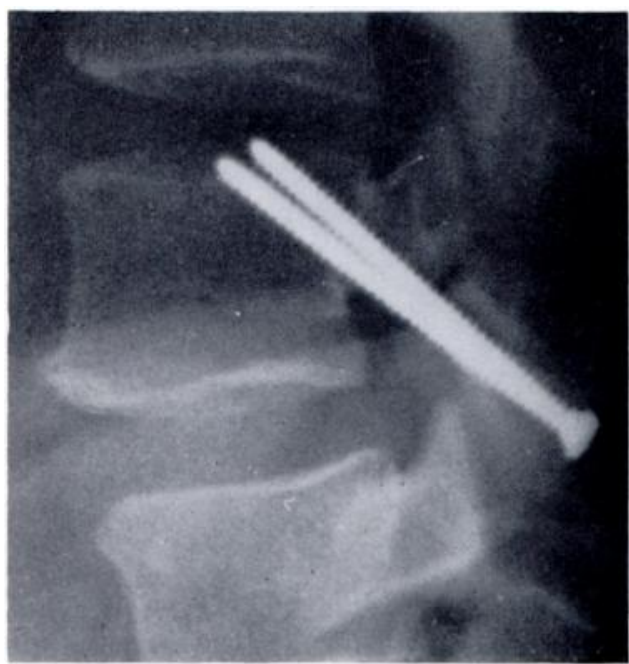

FIG. 15

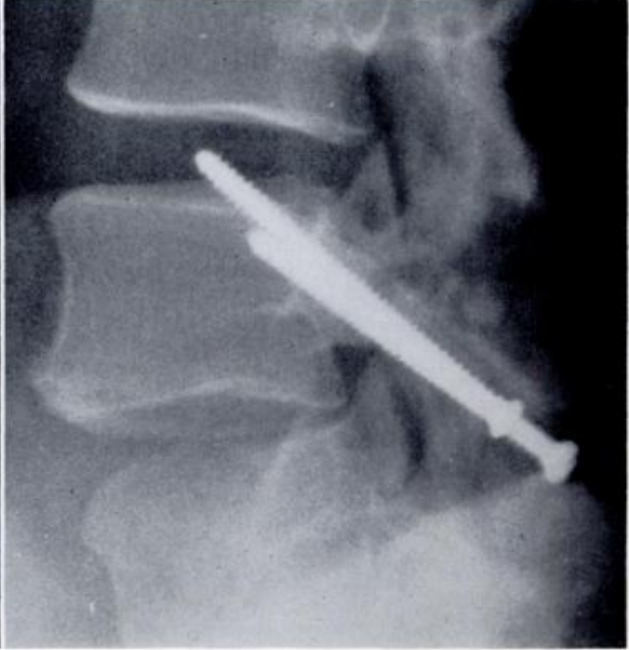

Fig. 16

Case 5. Figure 15-Early post-operative radiograph. Figure 16-Three months later. The defect has healed. In this case the screws were too long. The patient developed mild sciatic symptoms which were relieved by removal of the offending screw.

earlier film, and showed that one of the screws was too long. Removal of the screw relieved the sciatica (Figs. 15 and 16). The disappearance of the defect is clearly shown in the second radiograph.

\section{COMMENT}

It is emphasised that by no means every patient with spondylolisthesis requires operation. Many patients are able to lead a fully active life, including strenuous physical exercise, without disabling symptoms. Operation directed towards eliminating the defect of the pars interarticularis seems more logical than the standard and more drastic operation of local spinal fusion. The operation is probably applicable, however, only to cases in which the gap in the neural arch is less than three or four millimetres. One of the advantages of the method is that it may be abandoned at any stage if anatomical circumstances do not appear to be propitious, and one of the other posterior approach operations may then be carried out.

\section{SUMMARY}

A method of repairing the defect in spondylolisthesis by internal fixation with screws and bone grafting is described. Sixteen patients have been operated upon with only one failure. In two cases the spine was re-explored for incidental complications and the defect was found to have fused solidly.

\section{REFERENCES}

Henderson, E. D. (1966): Results of the Surgical Treatment of Spondylolisthesis. Journal of Bone and Joint Surgery, 48-A, 619.

vol. 52 B, No. 3, AUgUST 1970 